\title{
Erratum to: Optical and Dielectric Properties of PVP Based Composite Polymer Electrolyte Films
}

\author{
S. K. Shahenoor Basha ${ }^{a}$, G. Sunita Sundari ${ }^{a}$, K. Vijay Kumar ${ }^{b}$, and M. C. Rao ${ }^{c, *}$ \\ ${ }^{a}$ Solid State Ionics Laboratory, Department of Physics, K. L. University, Guntur 522502, India \\ ${ }^{b}$ Department of Physics, Dayananda Sagar Academy of Technology and Management, \\ Udayapura, Bangalore 560082, India \\ ${ }^{c}$ Department of Physics, Andhra Loyola College, Vijayawada 520008, India \\ *e-mail: raomc72@gmail.com \\ Received July 4, 2019; revised July 4, 2019; accepted July 4, 2019
}

DOI: $10.1134 / \mathrm{S} 0965545 \mathrm{X} 19050225$

This erratum corrects the Figure 2 of the published paper. The results presented in the published paper are correct and are not affected by this change in Figure.

The original article can be found online at https://doi.org/10.1134/S0965545X17040095 


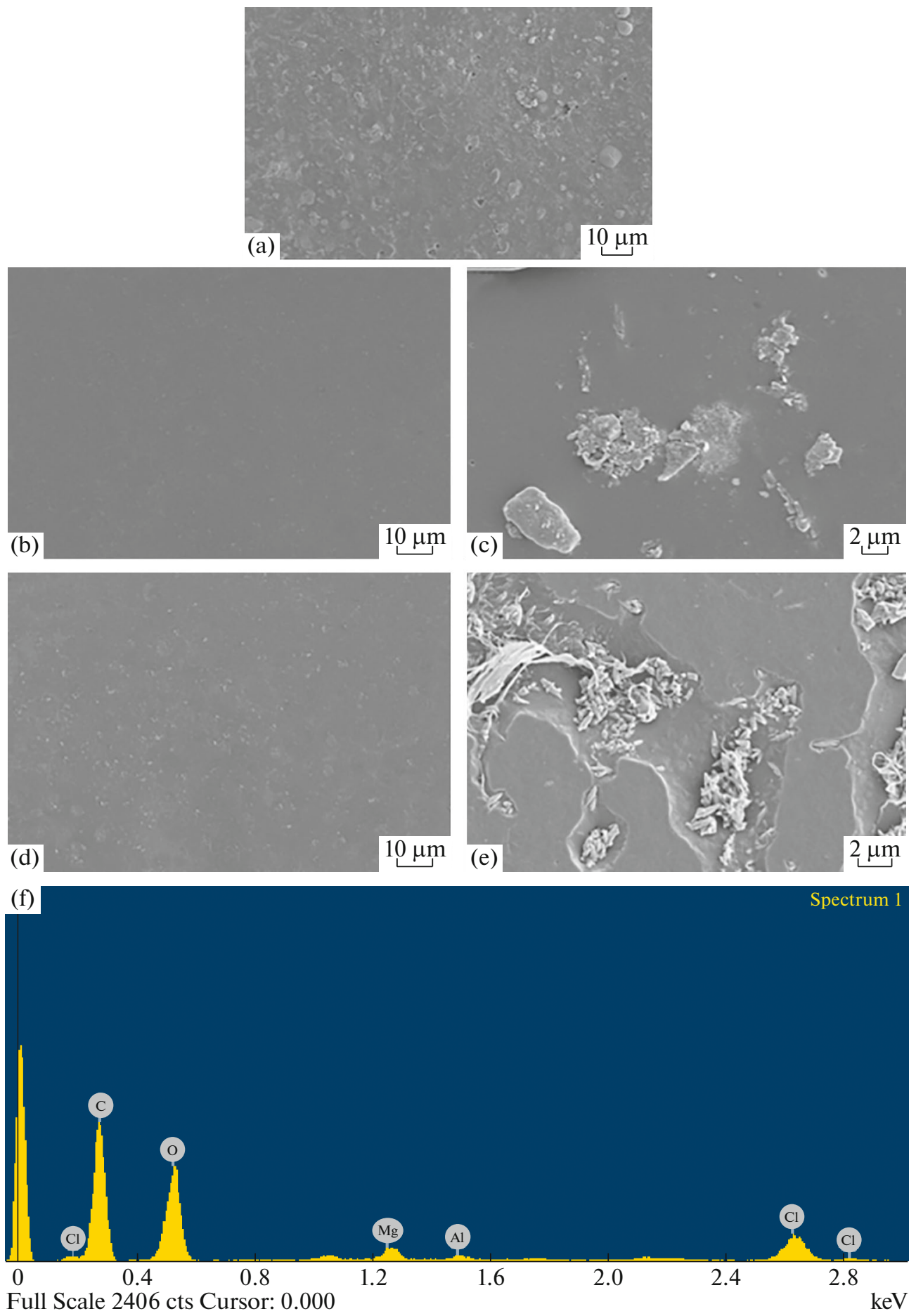

Fig. 2. (a-e) SEM and (f) EDS analysis of polymer electrolyte films for different wt\% ratios of PVP: (a) pure PVP, (b) (95: 5), (c) $(90: 10),(d)(85: 15),(e)(80: 20)$. 